\title{
A Rare and Unusual Case of Spontaneous Hemoperitoneum without any Etiology with Review of Literature
}

\author{
Hemant Atri* \\ Fortis Escorts Hospital, India \\ Submission: August 30, 2017; Published: August 13, 2018 \\ "Corresponding author: Hemant Atri, Fortis Escorts Hospital, Faridabad, India, Email: atri_hemant@yahoo.in
}

\begin{abstract}
Spontaneous hemoperitoneum is an uncommon cause of acute abdominal pain. There is a multiple cause for spontaneous hemoperitoneum and an underlying cause should always be looked. It is critical to identify this clinical picture and treat any active bleeding promptly [1]. We reported the first case in the literature (to our knowledge) of spontaneous hemoperitoneum without any etiology.
\end{abstract}

\section{Introduction}

Non-traumatic hemoperitoneum may occur spontaneously or may be iatrogenic. Spontaneous hemoperitoneum (SH) is a rare, but life-threatening condition of non-traumatic etiology. It usually occurs in patients with coagulation abnormalities because of hepatic, splenic, vascular or gynaecologic pathology [2]. It typically presents with signs of acute intraperitoneal bleeding and occasionally abdominal compartment syndrome in severe cases. Non-traumatic liver pathology such as hepatic adenomas, focal nodular hyperplasia, large hemangiomas, are considered as the most common cause of $\mathrm{SH}$, when gynecological causes are not considered.

Malignant hepatic lesions, either primary or metastatic, may also rupture spontaneously. These disorders are usually associated with anticoagulation, pregnancy as triggering factors. Spleen is the second most common solid organ to give rise to SH followed by vascular causes which includes aneurysms, pseudoaneurysms, or arterial dissection. Endoscopic technique like Angiography and embolization almost always constitute firstline therapy in the hemodynamically stable patient. Surgery should be considered in those in whom interventional techniques have failed to control the bleeding, or patient has unresponsive hemorrhagic shock [3].

Hemorrhagic shock can be rapidly fatal. The primary goal is to stop the bleeding. Resuscitation may well depend on estimated severity of haemorrhage. Patients who have moderate hypotension from moderate bleeding may well benefit from a delay in massive resuscitation to reach a definitive care facility. When patients are obviously in severe hemorrhagic shock, the use of intravenous crystalloids or colloids and blood products can be lifesaving. A haemoglobin level of 7-8 $\mathrm{g} / \mathrm{dl}$ is an appropriate threshold for transfusion in critically ill patients with no risk factors for tissue hypoxia. Moreover, haemoglobin concentration should not be the only therapeutic guide in actively bleeding patients. Instead, therapy should be aimed at restoring intravascular volume and adequate hemodynamic parameters [4]. In nutshell, Gynecological, splenic, and hepatic etiologies are the most common $[5,6]$.

\section{Case Report}

A 23-year-old man was presented with complaints of severe pain in abdomen associated with loose stools since two days. Pain is more in suprapubic area, insidious in onset, gradually progressing, non-radiating associated with abdominal distension and decreased urine output. No complaints of nausea, vomiting or fever. There was no significant past medical, surgical ,drug intake or family history. No history of any trauma. His USG abdomen done (outside) suggestive of free fluid seen in peritoneal cavity more in RIF? burst appendix/intestinal perforation (rule out) for which he was operated outside, but patient was referred to our hospital in view of intraoperative findings(outside) which were -approximately 1 litre of blood present with clots in RIF with active uncontrolled bleed.

Drain was placed, and abdomen was closed. His vitals in emergency were temperature-afebrile, pulse-112/minute, blood preesure-140/90, spo2-99\% on room air. Patient is conscious, 
alert and well oriented. His abdomen was distended, generalized tenderness with guarding and rigidity present, abdominal drain had approx $75 \mathrm{ml}$ of fresh blood with post-laparatomy scar in lower abdomen with dressing over it with foley's in-situ. Patient was shifted to ICU then to OT with a consent of exploratory laparotomy and proceed. On admission his bleeding time-1.45, clotting time-6.10, creatinine-0.86, PT/INR-14.1/1.13,Hb-11.3g/ dl,TLC-13.3,platelet count-202 thou/ul, LFT and other blood investigations are within normal range.
His intraoperative findings were approximately $500-600 \mathrm{ml}$ blood present in peritoneal cavity, thickened swollen appendix present (not perforated) echymotic macular spots present over bladder and rectum, no obvious bleeding/blood staining present in peritoneum, mesentry or retroperitoneum, no bowel or any solid organ injury noted. Postoperatively repeated haemoglobin and other blood tests were done which were within normal limits without any significant fall in haemoglobin. His CECT whole abdomen done postoperatively to look for any missed injury (Figure 1 \& 2).
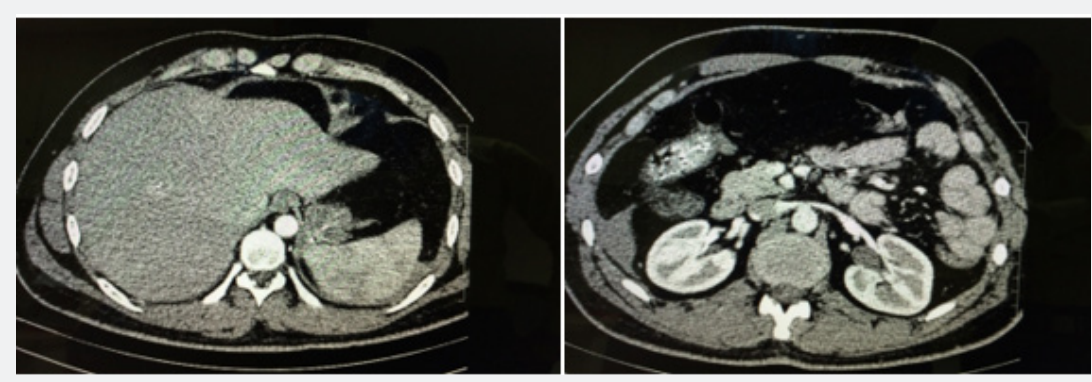

Figure 1: Postoperatively repeated haemoglobin.
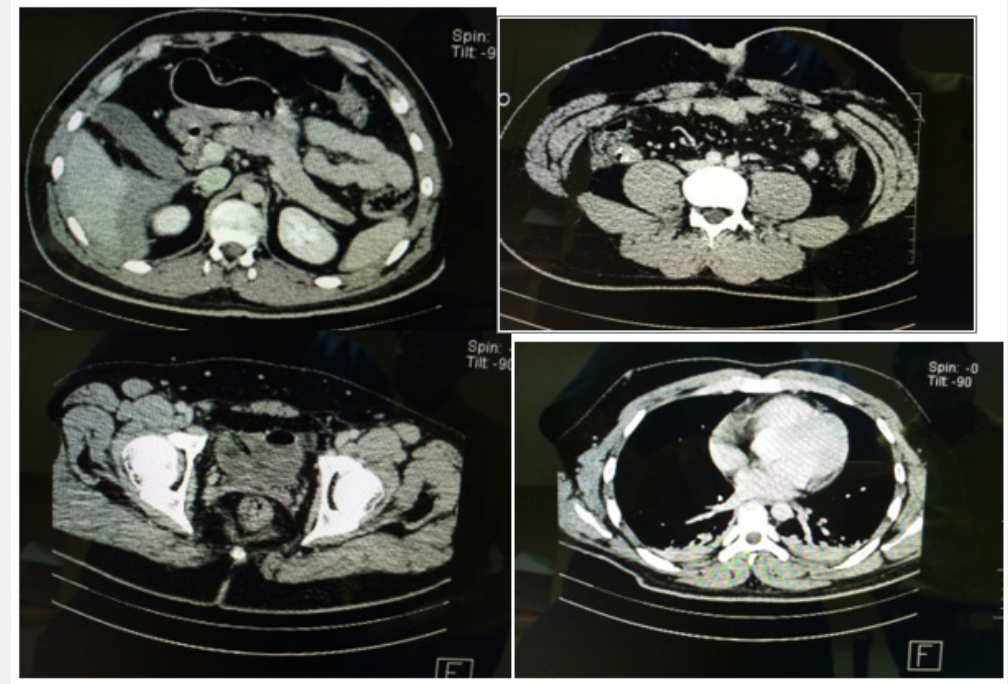

Figure 2: CECT whole abdomen done postoperatively to look for any missed injury.

Physician consultation was also taken to rule out any bleeding diathesis, but tests done till 6th postoperative day were within normal range without any significant fall in haemoglobin. Postoperative period was uneventful, and patient was discharged in stable condition.

\section{Conclusion}

Spontaneous hemoperitoneum is a rare cause of acute abdomen. There are multiple causes causing Spontaneous hemoperitoneum. Gynecological, splenic, and hepatic etiologies are the most common. It is critical to identify this clinical picture and treat any active bleeding promptly. Surgery is the treatment of choice. In our case we are not able to find any cause of Spontaneous hemoperitoneum.

\section{References}

1. Lubner M, Menias C, Rucker C, Bhalla S, Peterson CM, et al. (2007) Blood in the belly: CT findings of hemoperitoneum. Radiographics 27(1): 109125.

2. Moore CH, Snashall J, Boniface K (2012) Spontaneous splenic hemorrhage after initiation of dabigatran (radaxa) for atrial fibrillation. Am J Emerg Med 30(9): 2082.

3. Kasotakis G (2014) Spontaneous Hemoperitoneum. Surg Clin N Am 94(1): 65-69.

4. Gutierrez G, Reines HD, Marian Wulf-Gutierrez E (2004) Clinical review: hemorrhagic shock. Critical Care 8(5): 373-338.

5. Lucey BC, Varghese JC, Anderson SW, Soto JA (2007) Spontaneous hemoperitoneum: a bloody mess. Emerg Radiol 14(2): 65-75.

6. Lucey BC, Varghese JC, Soto JA (2005) Spontaneous hemoperitoneum: causes and significance. Curr Probl Diagn Radiol 34(5): 182-195. 


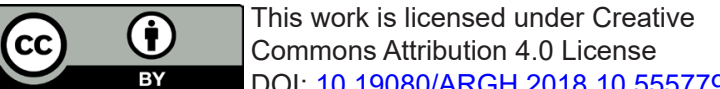

BY

DOI: 10.19080/ARGH.2018.10.555779

\section{Your next submission with JuniperPublishers will reach you the below assets}

- Quality Editorial service

- Swift Peer Review

- Reprints availability

- E-prints Service

- Manuscript Podcast for convenient understanding

- Global attainment for your research

- Manuscript accessibility in different formats

( Pdf, E-pub, Full Text, audio)

- Unceasing customer service

Track the below URL for one-step submission https://juniperpublishers.com/online-submission.php 